\title{
Coenzyme Q10
}

National Cancer Institute

\section{Source}

National Cancer Institute. Coenzyme Q10. NCI Thesaurus. Code C916.

A naturally occurring benzoquinone important in electron transport in mitochondrial membranes. Coenzyme Q10 functions as an endogenous antioxidant; deficiencies of this enzyme have been observed in patients with many different types of cancer and limited studies have suggested that coenzyme Q10 may induce tumor regression in patients with breast cancer. This agent may have immunostimulatory effects. ( $\mathrm{NCl04)}$ 